\title{
Propulsion Drive Models for Full Electric Marine Propulsion Systems
}

\author{
Judith M. Apsley, Member, IEEE, Aurelio González-Villaseñor, Mike Barnes, \\ Alexander C. Smith, Senior Member, IEEE, Steve Williamson, Fellow, IEEE, Jeroen D. Schuddebeurs, \\ Patrick J. Norman, Campbell D. Booth, Graeme M. Burt, Member, IEEE, and J. R. McDonald, Member, IEEE
}

\begin{abstract}
Integrated full electric propulsion systems are being introduced across both civil and military marine sectors. Standard power system analysis packages cover electrical and electromagnetic components but have limited models of mechanical subsystems and their controllers. Hence, electromechanical system interactions between the prime movers, power network, and driven loads are poorly understood. This paper reviews available models of the propulsion drive system components: the power converter, motor, propeller, and ship. Due to the wide range of time constants in the system, reduced-order models of the power converter are required. A new model using state-averaged models of the inverter and a hybrid model of the rectifier is developed to give an effective solution combining accuracy with speed of simulation and an appropriate interface to the electrical network model. Simulation results for a typical ship maneuver are presented.
\end{abstract}

Index Terms-Electromechanical interactions, marine, propulsion, rectifier models.

\section{INTRODUCTION}

$\mathbf{I}$ NTEGRATED full electric propulsion (IFEP) systems for marine applications are being intensively developed in both commercial and military shipping sectors. Replacement of direct mechanical couplings between the prime mover and propeller with an electrical network offers potential benefits including reduced fuel consumption, enhanced dynamic performance, increased reliability, reduced maintenance costs, and greater flexibility in the ship layout. These benefits depend on the operational duties of the ship and the nature of any other electrical loads.

Paper IPCSD-08-055, presented at the 2007 IEEE International Electric Machines and Drives Conference, Antalya, Turkey, May 3-5, and approved for publication in the IEEE TRANSACTIONS ON INDUSTRY APPLICATIONS by the Electric Machines Committee of the IEEE Industry Applications Society. Manuscript submitted for review October 1, 2007 and released for publication June 19, 2008. Current version published March 18, 2009.

J. M. Apsley, A. González-Villaseñor, M. Barnes, and A. C. Smith are with the School of Electrical and Electronic Engineering, The University of Manchester, Manchester, M60 1QD, U.K. (e-mail: j.apsley@ manchester.ac.uk, a.gonzalez@manchester.ac.uk; mike.barnes@manchester.ac.uk; sandy.smith@ manchester.ac.uk).

S. Williamson is with the University of Surrey, Guildford, GU2 7XH, U.K. (steve.williamson@surrey.ac.uk).

J. D. Schuddebeurs, P. J. Norman, C. D. Booth, G. M. Burt, and J. R. McDonald are with the Institute for Energy and Environment, Department of Electronic and Electrical Engineering, University of Strathclyde, Glasgow, G1 1XW, U.K. (e-mail: jeroen.schuddebeurs@eee.strath.ac.uk; pnorman@eee.strath.ac.uk; c.booth@eee.strath.ac.uk; g.burt@eee.strath.ac.uk; j.mcdonald@eee.strath.ac.uk).

Digital Object Identifier 10.1109/TIA.2009.2013569

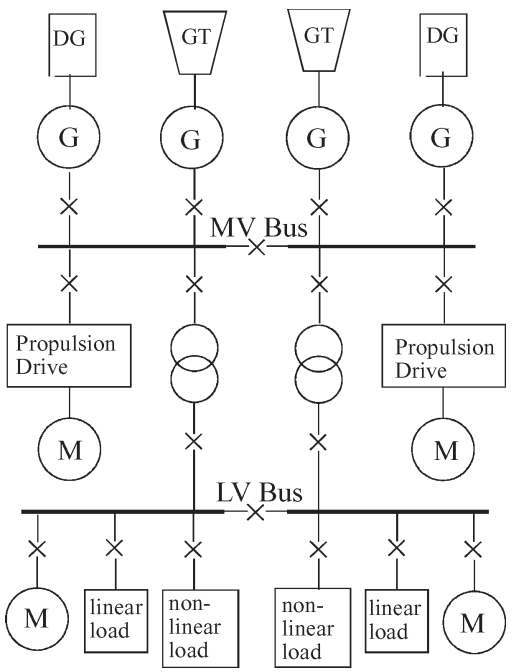

Fig. 1. Overview of an integrated full electric propulsion system.

Simulation tools for marine propulsion systems have been developed for through-life energy management, ship handling, and electrical network analysis [1]-[4]. However, interactions between the dominant mechanical systems and the electrical network are poorly understood. Hence, there is a need to include the prime movers and driven loads with the network model [5]-[7] in order to develop integrated control and protection strategies. Hitherto, research has either focused on improving the accuracy of a very particular part of the drive or ship subsystem (neglecting the difficulty of interfacing such a detailed model to the rest of the system) or adopted a broad-brush approach to the system (neglecting system fidelity). The Advanced Marine Electric Propulsion Systems (AMEPS) project is a collaboration between three U.K. universities (Strathclyde, Cranfield, and Manchester), bringing together expertise in gas turbines, power systems, machines, and drives to develop appropriate models of the complete IFEP system. This paper concentrates on models of the propulsion system and their interface with the electrical network.

\section{System Overview AND CONSTRAints}

Fig. 1 shows an overview of an IFEP system, where the gas turbine alternators (GT) and driven loads are connected to a fixed-frequency ac power network. This allows the gas turbines to be optimized for a single speed. Diesel generation (DG), e.g., for in-port operation, is also shown. Other than the main 


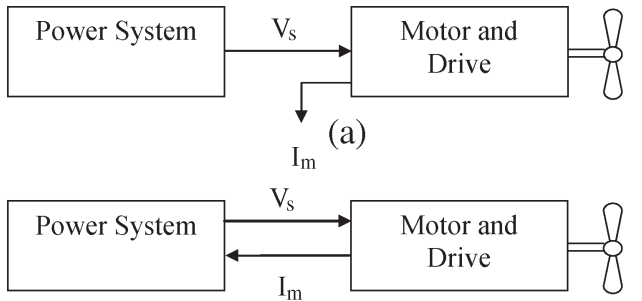

(b)

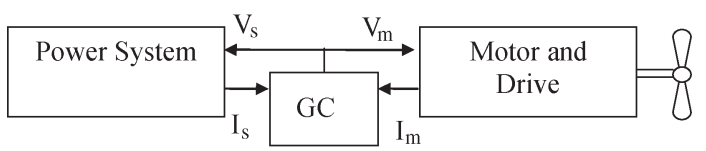

(c)

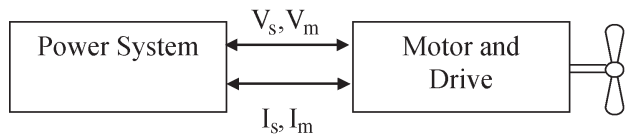

(d)

Fig. 2. Data flow at the drive-network interface. (a) Unidirectional interface. (b) Bidirectional interface with unidirectional variables. (c) Variable matching at the interface. (d) Bidirectional interface with bidirectional variables.

propulsion drives, there may be additional electrical loads, including hotel loads and pump and hoist drives.

\section{A. Interface Constraints}

In order to investigate interactions between these mechanical and electrical systems, the interfaces between these systems must be bidirectional. When an event occurs in one subsystem (for example, a change in operating point or a fault condition), then connected subsystems may be affected. The simulation should represent both the effect on other connected subsystems and their interaction with the part where the event originated.

Fig. 2 shows the interface requirements between the electrical network and propulsion drives. The four cases show increasing levels of complexity.

In (a), the electrical network voltage at the drive terminals may be time varying, but because the drive current is not fed back into the network model, there is no way of computing the network response to changes in the propulsion system. Many averaged-value rectifier models essentially follow this pattern, assuming ideal voltage sources and fixed network impedances, which do not respond to changes in the driven load [8]. Even where the averaged-value rectifier models have been extended to determine ac-side current waveforms and incorporate generator characteristics [9], these rely on calculating a lumpedparameter equivalent circuit (EC) of the power network. This is not suitable in the present application because it does not allow for connection or disconnection of additional loads and generators.

Case (b) allows two-way data flow but with unidirectional variables: Voltage is set by the network, and the returned current is defined by the driven load. This case is desirable because it is easy to implement, avoiding arithmetic loops and convergence problems.

In case (c), both subsystems source currents, and an additional general control (GC) block is required to match currents
TABLE I

PROPULSION DRIVE TIMINGS

\begin{tabular}{|l|l|}
\hline Source & Time \\
\hline Semiconductor commutation & $\sim 1 \mu \mathrm{s}$ \\
\hline Stator leakage time constant & $1-10 \mathrm{~ms}$ \\
\hline Rotor time constant & $50 \mathrm{~ms}-1 \mathrm{~s}$ \\
\hline PWM period & $0.5-2 \mathrm{~ms}$ \\
\hline PWM resolution (12 bit) & $\sim 1 \mu \mathrm{s}$ \\
\hline DC link ripple period & $2.8 \mathrm{~ms}$ \\
\hline Propeller run-up time & $20-60 \mathrm{~s}$ \\
\hline Ship run-up time & $60-500 \mathrm{~s}$ \\
\hline Wave disturbance interval & $10-100 \mathrm{~s}$ \\
\hline * Based on 0.5-20MW Industrial drives and rapid response ship.
\end{tabular}

at the interface. GC might represent a network with line reactance, using capacitive snubbers for current matching between the power network and the drive system. In [10], GC is an explicit current-matching control element.

Case (d) is the most complex since either side of the interface may define the voltages and currents and the interface must control how this occurs. An example is the diode rectifier, where turn-on is defined by voltage and turn-off is set by current.

\section{B. Timing Constraints}

Table I shows typical timing values within the marine propulsion drive, based on a generic 20-MW propulsion motor, and rapid-response ship. The discrepancy between time constants in the power converter and the driven load is apparent. If the entire system is modeled at a time step to suit the power semiconductors, for the duration of a mechanical transient, simulation run times become excessive. One solution is to have reduced-order models of the power converter to allow a larger step size. Multirate simulation may be used to minimize the number of calculations at the highest rate.

\section{Software Constraints}

The Simulink SimPowerSystems toolbox was selected as the simulation environment for the power network. Other parts were modeled directly in Simulink or via its interface to Fortran in order to take advantage of existing validated models.

\section{Simulation Models}

An overview of the propulsion drive model is shown in Fig. 3. This combination was selected from a range of possible technologies [7] for its immediate relevance to U.K. marine users. However, the model has been structured in subblocks to allow future extension to alternative motors or power converters. From the rectifier onward, the connections between model elements are deterministic, with no conflicts between inputs and outputs. Bidirectional data flow is achieved with unidirectional variables, as outlined in Section II-B. The main models are discussed in the following.

\section{A. Inverter}

A voltage-source inverter with a diode or thyristor rectification stage is modeled. For the inverter stage, an 


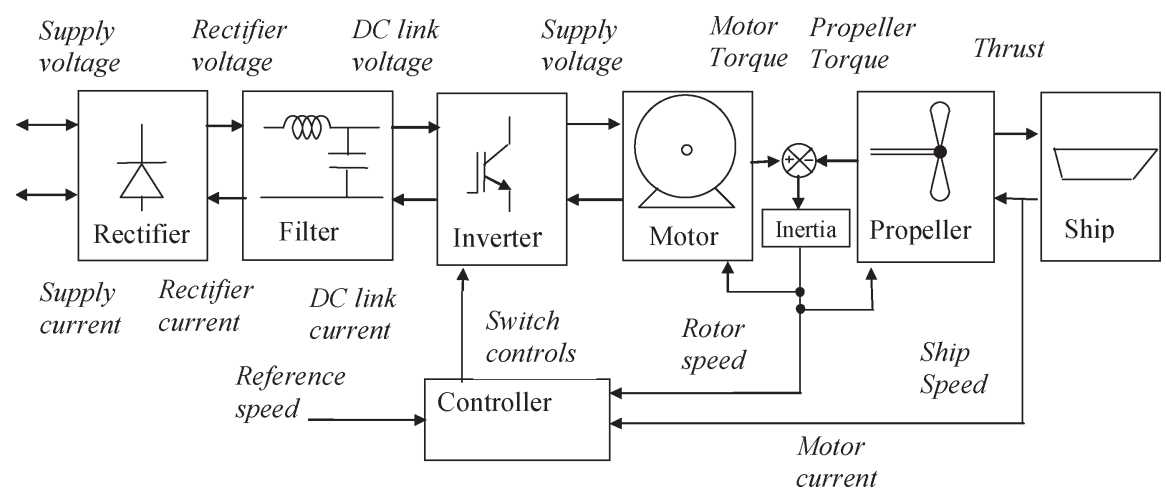

Fig. 3. Marine propulsion drive simulation structure.

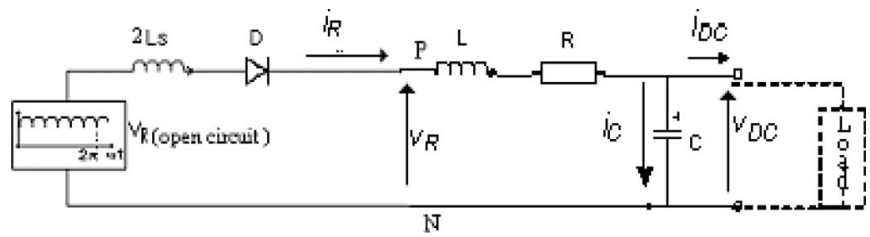

Fig. 4. EC model of the rectifier.

averaged-voltage-vector approach is proposed. Space-vector pulsewidth modulation approximates the desired voltage vector by using a sequence of switch states over the switching period. The time for which each state is asserted is weighted to give the desired average voltage over the switching period. A model using the averaged voltage vector instead of the switch states avoids the need to accurately locate switching edges but neglects the effects of PWM harmonics. Inverter dead time has not been included, although it could be added using the analysis in [11]. The resulting model thus loses some accuracy but can be run at a fixed rate equal to the inverter switching period (typically $0.5-2 \mathrm{~ms}$ ). This is a significant improvement in time step and can also be used to include control loop delays.

\section{B. Rectifier}

The averaged-voltage-vector technique cannot be applied to the diode rectifier, because the turn-on and turn-off instants depend on the circuit conditions rather than external control signals. Averaged-value rectifier models which assume fixed power network conditions were rejected because they do not meet the interface constraints discussed in Section II.

1) EC Model: Two models have been considered for the ship propulsion drive. The first uses separate EC models for the ac and dc sides. The dc-side voltage is calculated, assuming that there are only two diodes conducting at any time, neglecting overlap. In this case, the rectifier and dc link can be represented by the circuit model in Fig. 4, where the voltage source $\left(V_{R}\right)$ represents the maximum envelope of the three-phase supply voltages; $\mathrm{Lr}, R$, and $C$ are the dc-link inductance, resistance, and capacitance, respectively; and Ls is the line inductance. This is similar to the averaged-value rectifier models (e.g., [8] and [9]), except that the voltage source is defined from terminal connections rather than assumed network conditions. The circuit equations can be used to compute dc output voltage $\left(V_{\mathrm{DC}}\right)$ and rectifier current $\left(i_{R}\right)$ for a defined load current $\left(i_{\mathrm{DC}}\right)$.
Two methods have been considered for calculating the acside currents. In either case, additional circuit components are required to interface the current sources to SimPowerSystems. Fig. 5 shows the connection to the ac network. The measured envelope of the network voltages $\left(V_{s}\right)$ is used by the dc-side circuit, from which the ac-side currents $\left(I_{s}\right)$ can be calculated. The currents are injected into the power network using controlled current sources. The $R C$ circuits allow current matching across the interface, as discussed in case 2(c). The $R C$ component sizes are discussed in Section III-B3.

The simplest alternative is the power balance model, which equates input and output powers. This assumes unity power factor, which is almost true for a three-phase rectifier [12], but neglects the poor form factor. Hence, the model is not valid for peak current calculations, particularly with a stiff supply. The supply-side currents are calculated assuming a balanced starconnected resistive load equivalent to the output power.

Alternatively, a logic block may be used to assign the current drawn by the rectifier $\left(I_{R}\right)$ to the supply lines that are conducting, assuming that there are only two diodes conducting at any time. A full six-diode model was also considered, with an extended logic block which allowed three diodes to conduct simultaneously, but was found to give complicated algebraic loops; loop-breaking solutions caused erroneous commutation in continuous conduction mode.

2) Hybrid Model: The second model is a hybrid, combining the library model of a rectifier from SimPowerSystems with a Simulink state-space model of the dc link (Fig. 6). $V_{R}$ is the output of the diode bridge library model, and $I_{\mathrm{DC}}$ is set by the load. The state variables of the dc link are the dclink voltage $V_{\mathrm{DC}}$ and rectifier current $I_{R}$. A controlled current source of value $I_{R}$ is connected to the SimPowerSystems rectifier model. This moves the interface between the power system circuit model and the drive from the ac side to the dc link and reduces it to the form of interface given in case 2(b). As Fig. 6 shows, the supply defines the voltage applied to the rectifier, and the dc side defines the current returned. Within the SimPowerSystems rectifier library block, local snubber values are specified for each power diode. These were sized to reflect realistic component values at $1 \mu \mathrm{F}$ and $1 \mathrm{k} \Omega$.

3) Evaluation of Rectifier Models: The models were implemented and compared with an independent model using the PLECS simulation package [13]. For the tests, three values of supply impedance were considered: an ideal source with 


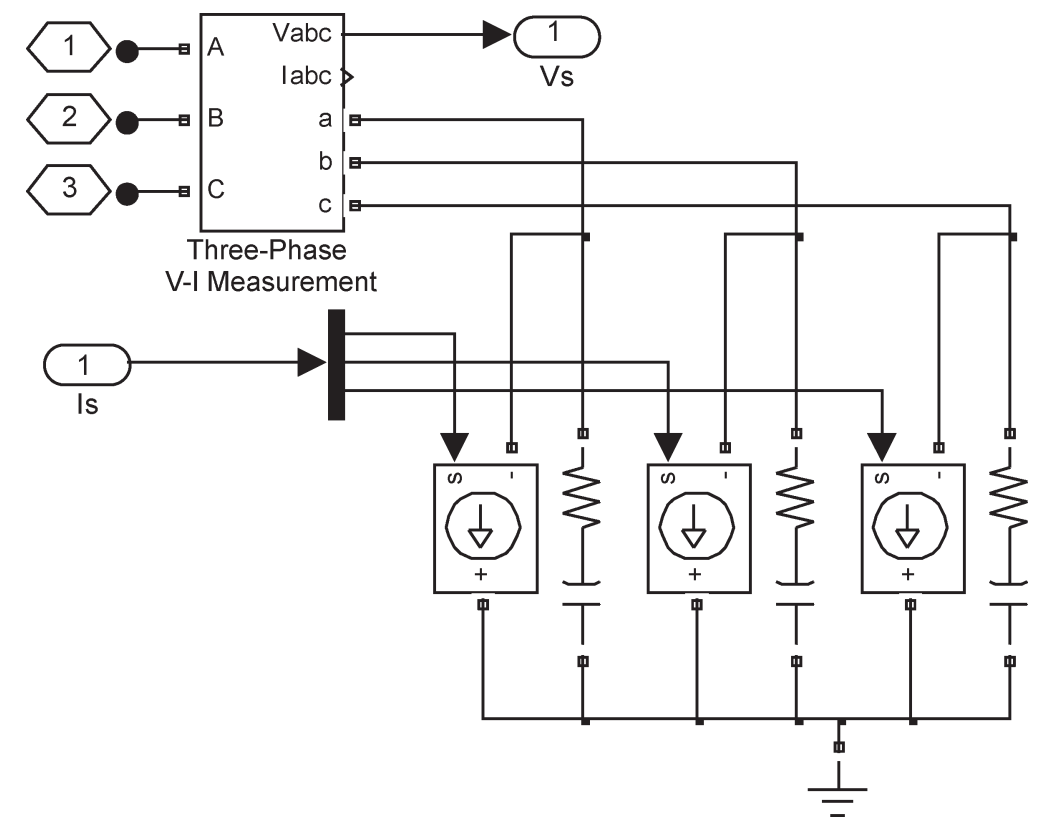

Fig. 5. Circuit components to interface with SimPowerSystems.

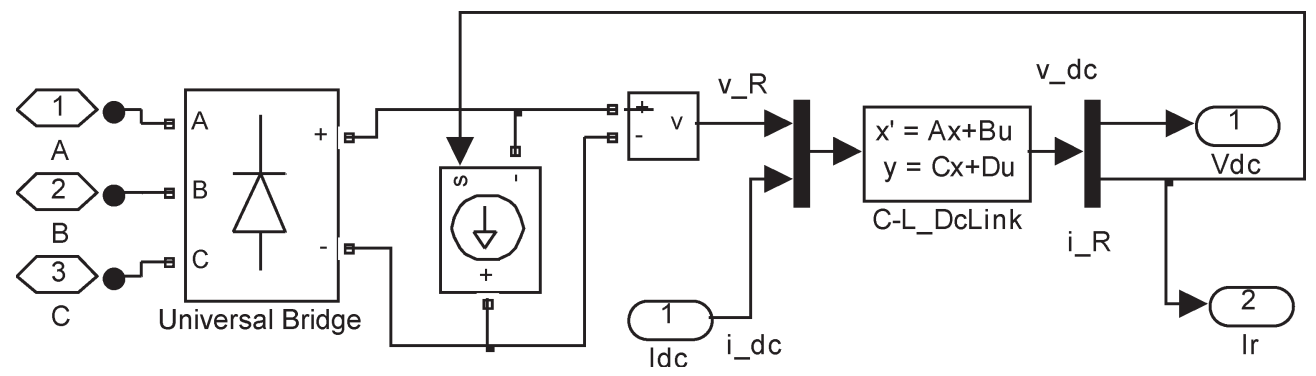

Fig. 6. Implementation of the hybrid rectifier model.

TABLE II

COMPARISON OF SUPPLY CURRENT HARMONIC DistorTION BETWEEN THE PLECS AND EQUIVALENT CIRCUIT MODELS

\begin{tabular}{|c|c|c|c|}
\hline Conditions & Model & $I_{R \text { fund }}(\mathrm{A})$ & THD $_{\mathrm{I}}(\%)$ \\
\hline \multirow{2}{*}{$\begin{array}{l}\text { Ideal source, } \\
\text { discontinuous } I_{R}\end{array}$} & Plecs & 997.3 & 79.28 \\
\hline & E.C. & 997.3 & 79.28 \\
\hline \multirow{2}{*}{$\begin{array}{l}\text { Ideal source, } \\
\text { continuous } I_{R}\end{array}$} & Plecs & 2418 & 48.88 \\
\hline & E.C. & 2418 & 48.88 \\
\hline \multirow{2}{*}{$\begin{array}{l}\text { Stiff source, } \\
\text { discontinuous } I_{R}\end{array}$} & Plecs & 1009 & 82.73 \\
\hline & E.C. & 1009 & 82.82 \\
\hline \multirow{2}{*}{$\begin{array}{l}\text { Stiff source, } \\
\text { continuous } I_{R}\end{array}$} & Plecs & 2424 & 54.56 \\
\hline & E.C. & 2418 & 48.89 \\
\hline \multirow{2}{*}{$\begin{array}{l}\text { Weak source, } \\
\text { discontinuous } I_{R}\end{array}$} & Plecs & 144.3 & 79.76 \\
\hline & E.C. & 143.1 & 78.72 \\
\hline \multirow{2}{*}{$\begin{array}{l}\text { Weak source, } \\
\text { continuous } I_{R}\end{array}$} & Plecs & 2208 & 22.38 \\
\hline & E.C. & 2397 & 29.99 \\
\hline
\end{tabular}

no line impedance, a stiff source with $1.5 \%$ reactance, and a weak source of $15 \%$ reactance (with a $20-\mathrm{MV}$. A base). The ODE23tb integration method was used, with a maximum step size of $100 \mu \mathrm{S}$.

Table II compares harmonic distortion between the reference PLECS model and the EC (diode logic) model. Results for the hybrid model have been omitted because they were indistinguishable from the reference PLECS model in all cases. As might be expected, the assumption that overlap can be neglected is not significant for a stiff source and with discontinuous conduction but makes a significant difference to line currents in continuous conduction mode, particularly with a weak source. This is shown in Fig. 7, which compares supply-side line to neutral voltages and line currents, for a stiff source in continuous conduction mode.

The results presented so far are for the Simulink-only model, with the voltage source represented as an ideal signal. When the model was embedded in the power network, using the interface shown in Fig. 5, the model gave increasing problems as the line inductance was increased. With a stiff source, current-matching $R C$ circuit values of $10 \mathrm{mF}$ and $1 \Omega$ gave a stable simulation. Larger values of resistance and lower values of capacitance gave excessive simulation times or led to convergence problems. However, the resulting current flowing through the current-matching circuits was considerable and caused excessive distortion to waveforms. In the case of a weak source, the current-matching values required for the model to stably run produced such large leakage currents in that they became the dominant feature in the waveforms, making the model ineffective and the EC approach unsuitable.

By contrast, the hybrid model was found to run effectively. Even with continuous conduction and a weak supply, the results were indistinguishable from the PLECS reference model, as shown in Fig. 8. Simulation times were also comparable, for example, within $10 \%$ for a strong source. 

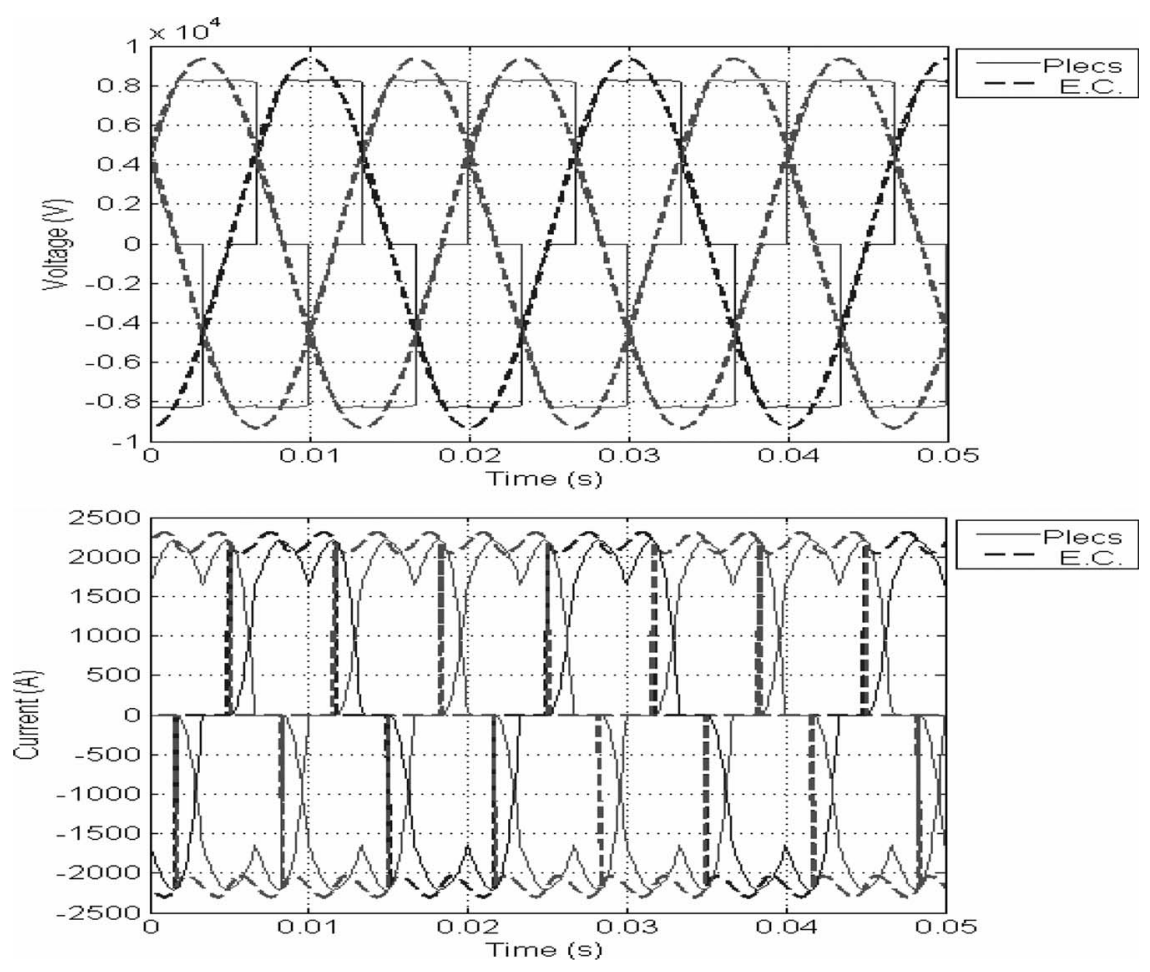

Fig. 7. Comparison of supply line to (upper) line voltages and (lower) line currents between the PLECS and EC models.
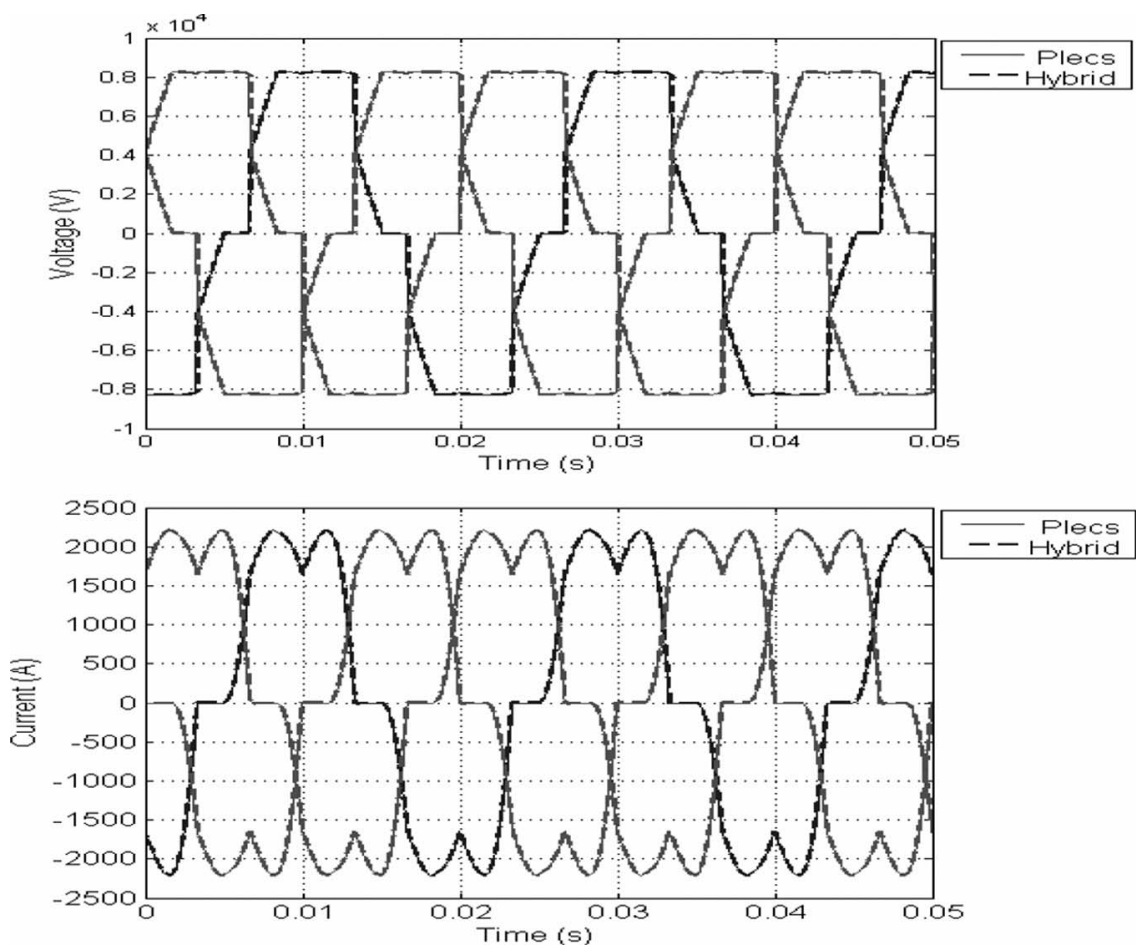

Fig. 8. Comparison of supply line to (upper) line voltages and (lower) line currents between the PLECS and hybrid models.

\section{Motor}

Multiphase induction machines are used in marine propulsion drives because of their inherent fault tolerance and reduced power rating per phase. They may also give better efficiency and smoother torque. Reference [14] shows that, for a multiphase machine, the Park transformation can be replaced by a general symmetric-component transformation. For an $m$-phase machine with an odd number of phases, the stator phases are transformed into $(m-1) / 2 d q$ sets and one zero-sequence set. For ideal sinusoidal windings, only the fundamental $d q$ set produces a net stator $\mathrm{mmf}$ and creates torque. Hence, the multiphase machine may be controlled in the same way as a three-phase machine, with $m-2$ additional constraints in that all higher order and zero-sequence currents are kept to zero 
[15], since these sequence sets contribute only to motor losses. For clarity, only the expressions for an odd number of phases are given in the following:

$$
\mathbf{x}_{d q 0}=\mathbf{T} \mathbf{x}_{a b c}
$$

where

$$
\begin{array}{ll}
\mathbf{x}_{a b c} & {\left[x_{a}, x_{b}, x_{c}, \ldots, x_{m}\right]^{\mathrm{T}} ;} \\
\mathbf{x}_{d q 0} & {\left[x_{d 1}, x_{q 1}, x_{d 3}, x_{q 3}, \ldots, x_{d(m-2)}, x_{q(m-2)}, x_{0}\right]^{\mathrm{T}} ;} \\
T_{k, l} & \sqrt{2 / m} \cos [(k+1)(l-1) \alpha / 2] \text { for } k \text { odd; } \\
T_{k, l} & \sqrt{2 / m} \sin [k(l-1) \alpha / 2] \text { for } k \text { even. }
\end{array}
$$

$k$ and $l$ vary from one to $m$, and the displacement between phases is $\alpha=2 \pi / m . \mathbf{x}_{a b c}$ and $\mathbf{x}_{d q 0}$ may represent any motor electromagnetic variable (for example, voltage, current, and flux linkage) in the winding and transformed coordinate spaces, respectively.

The fundamental $d q$ motor equations are identical to those for a three-phase machine. The additional higher order and zero-sequence sets do not include any rotor variables since there is no rotor excitation in these sets and they are decoupled in the stationary reference frame

$$
\mathrm{v}_{d q s(2 n-1)}=\mathrm{R}_{s} \mathrm{i}_{d q s(2 n-1)}+p \mathrm{Ll}_{s} \mathrm{i}_{d q s(2 n-1)}
$$

where $n=2, \ldots,(m-1) / 2$.

The model assumes rotor-flux-oriented control and orients rotor flux by the slip calculator method as representative of the operating envelope and bandwidth of the machine.

As with the three-phase case, the $d q$ model neglects winding harmonics, although the extension to concentrated winding or synchronous PM machines would be relatively minor, as models for these machines are well documented and the mapping to higher order $d q$ sets and their current control is already in place. For example, [16] is for a synchronous reluctance machine, demonstrating the wider application of the general symmetriccomponent transformation to other machine technologies. Each additional harmonic increases the order of the motor model by two.

The averaged-voltage-vector approach omits PWM harmonics, which can contribute additional copper losses and pulsating torques. For a given PWM strategy and winding arrangement, pulsating torques may be calculated offline using complex harmonic analysis [17] and injected as a disturbance torque. With a balanced supply and machine, the frequency of these pulsations $f_{p}$ is an even multiple of the product of the number of phases and the principal excitation frequency $f_{e}$. Calculation of the magnitude requires knowledge of both the stator current waveform and the machine winding distribution, as given in [17]

$$
f_{p}=2 m f_{e} .
$$

The omission of stator harmonic losses, iron losses, and also of power electronic switching losses was considered acceptable since the focus was on electromechanical interactions rather than efficiency and loss calculations.

\section{Driven Load}

The propeller model calculates torque $(Q)$ and thrust $(T)$ from nondimensional torque and thrust coefficients $K_{Q}$ and
$K_{T}$, respectively,

$$
T=\rho n^{2} D^{4} K_{T} \quad Q=\rho n^{2} D^{5} K_{Q}
$$

where $n$ is the propeller speed, $D$ is the propeller diameter, and $\rho$ is the water density.

The torque and thrust coefficients are a function of the propeller geometry and the nondimensional advance number $J$, which is the ratio of ship advance speed $V_{A}$ to propeller speed, given as $n D$ (in units of $2 \pi \mathrm{m} \cdot \mathrm{s}^{-1}$ )

$$
J=V_{A} / n \cdot D .
$$

The ship advance speed gives the approach speed of the water at the propeller inlet. It is less than the ship speed $V_{S}$ due to the wake. Full modeling of wake effects is complex, but the dominant term is frictional. The ship advance speed is calculated from the wake fraction $w$, which is a ship design parameter

$$
V_{A}=V_{S}(1-w) .
$$

For a family of propellers of similar geometry, torque and thrust can be calculated for a given combination of propeller and ship advance speeds. Tables of coefficients may be obtained from computational models or manufacturers' tests. The results in the following are based on the well-characterized Wageningen (Troost) B series of propellers, for which extensive test data are available [18]. Motor and propeller speeds are calculated using the normal equations of motion.

The test data in [18] are only valid for a limited range of positive advance numbers. For zero or negative propeller and ship advance speeds, modified torque and thrust coefficients are used as a function of advance angle $\beta$, which is the angle of the resultant of the propeller velocity and ship advance velocity, normally defined at a point that is $70 \%$ along the radius [18], [19]. Expressions for the torque and thrust and values for modified coefficients were obtained from [18]

$$
\beta=\tan ^{-1}\left[V_{A} /(0.7 \pi \cdot n \cdot D)\right] .
$$

The ship is treated as an inertial mass $m$, acted on by the sum of propeller thrusts $T$, with a resistive drag $R_{f}$ that is proportional to the square of ship velocity $V_{S}^{2}$. The normal equation of motion applies. Resistive drag can be calculated approximately from ship dimensions or obtained more accurately from the ship designers.

\section{VALIDATION}

The rectifier models were validated against the more-detailed independent commercial software package PLECS [13], as outlined in Section III. Motor and controller models have been tested by implementation on a multiphase laboratory test system [17] with a dSpace controller. The test machine was coupled to a dc load machine, which operated in speed control. Fig. 9 compares simulated and experimental results for a ramp change in flux current followed by a step in torque current for a six-phase machine. There is good agreement in predicted speed and currents. 


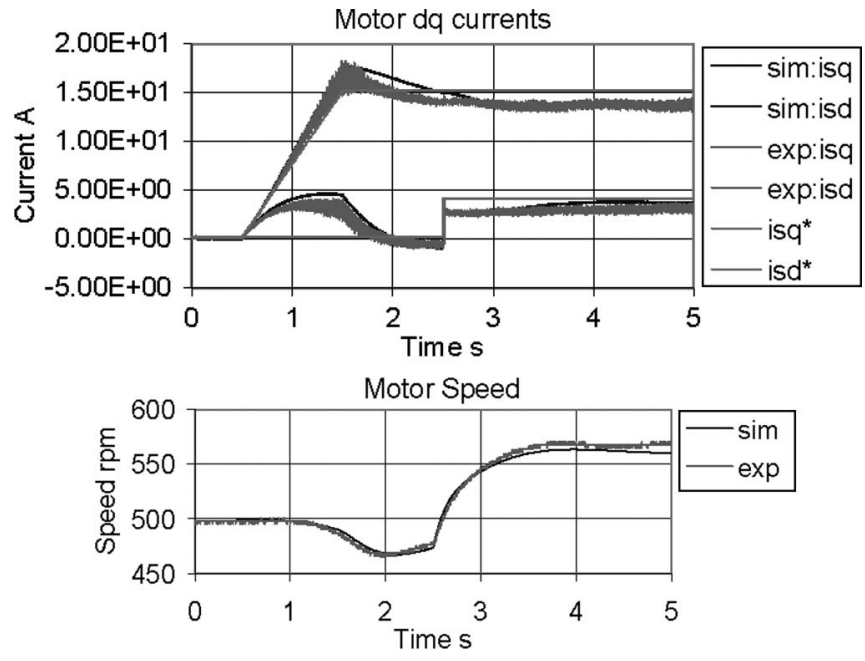

Fig. 9. Comparison of experimental (exp) and simulation (sim) results for a ramp-up in flux current (isd) followed by a step in torque current (isq).

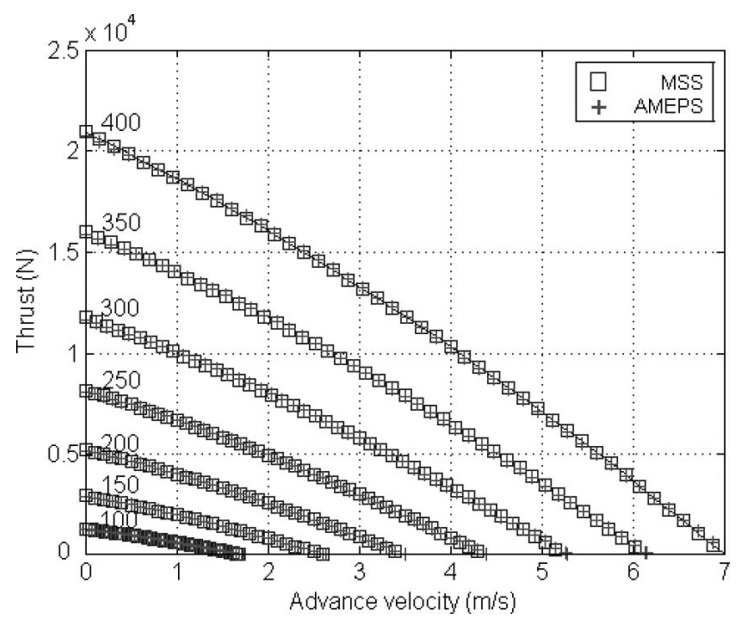

Fig. 10. Verification of calculated propeller thrust as a function of advance velocity.

The propeller models have been validated against the static performance curves in [18] and also compared with the results from the independent Marine Systems Simulator [2]. For example, Fig. 10 shows no discernible difference between the calculated thrusts from the two models.

\section{CAse Study}

Fig. 11 shows results from the propulsion system models for a ship accelerating to full speed. The 20-MW propulsion motor is limited to an operating envelope of $150 \%$ rated torque and $100 \%$ rated speed. The propeller accelerates much faster than the ship, and maximum torque and thrust occur as the propeller reaches its maximum speed. As the ship approaches full speed, the torque and thrust reduce. After $100 \mathrm{~s}$, a $0.1-\mathrm{Hz}$ thrust disturbance, with magnitude of $10 \%$ of the steady-state thrust, is applied. This is used to represent effects of high seas and, in extreme conditions, propeller emergence. Fig. 11 shows that the ship's speed is virtually unaffected because of its high inertia. However, the disturbance is clear in the motor torque and is passed back through to the supply current.

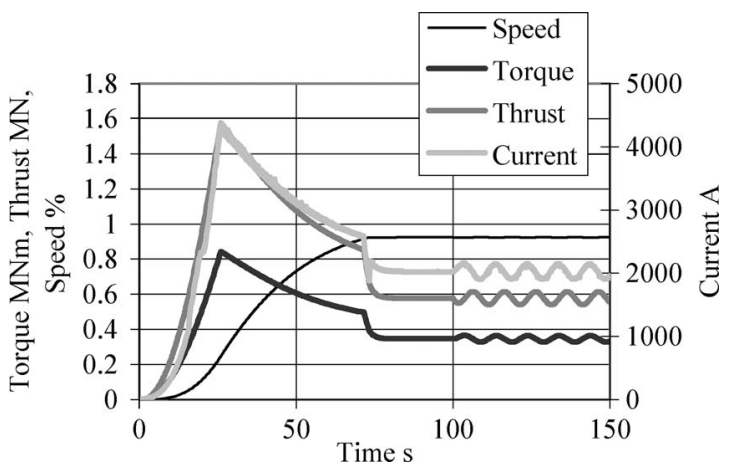

Fig. 11. Ship acceleration to full speed and response to disturbance thrust applied after $100 \mathrm{~s}$.

This has implications for the power network, which has been shown in a separate study [20] to be sensitive to low-frequency changes in load power, demonstrating the value of an integrated electromechanical simulation tool.

\section{CONCLUSION}

The limiting element in the propulsion drive model in terms of minimum time step and maximum computation times was found to be the power converter-specifically the interface with the power network. The best solution was found to be to locate the interface between the Simulink and power network models at the dc link, where current matching occurs in the dc-link capacitor. From this point onward, the drive system is deterministic, and reduced-order models can be used successfully. The SimPowerSystems rectifier model gave optimum results, as alternative theoretically better solutions could not be interfaced to the network without making compromises in the design.

The proposed drive system models have been used to show how load perturbations transfer to the electrical network. This is useful in itself for studying dc-link voltage regulation and propeller control strategies. The next step will be to look at the consequences for the complete IFEP system.

\section{ACKNOWLEDGMENT}

The authors would like to thank their colleagues at all three participating universities. This paper forms part of an EPSRC project (GR/S89562/01) on Advanced Marine Electric Propulsion Systems (AMEPS) between the Universities of Strathclyde, Manchester, and Cranfield, U.K.

\section{REFERENCES}

[1] T. Perez, N. Smogeli, T. I. Fossen, and A. J. Sørensen, "An overview of the Marine Systems Simulator (MSS): A Simulink Toolbox for marine control systems," Model. Identif. Control, vol. 27, no. 4, pp. 259-275, Oct. 2006.

[2] Marine Systems Simulator (MSS). Trondheim, Norway: Norwegian Univ. Sci. Technol. [Online]. Available: www.cesos.ntnu.no/mss

[3] Center for Advanced Power Systems. Gainesville, FL: Univ. Florida. [Online]. Available: http://www.caps.fsu.edu/repslist.asp

[4] Virtual Test Bed. Columbia, SC: Dept. Elect. Eng., Univ. South Carolina. [Online]. Available: http://vtb.engr.sc.edu

[5] A. Ouroua, L. Domaschk, and J. H. Beno, "Electric ship power system integration analyses through modeling and simulation," in Proc. IEEE Elect. Ship Technol. Symp., 2005, pp. 70-74.

[6] S. S. Kalsi and O. Nayak, "Ship electrical system simulation," in Proc. IEEE Elect. Ship Technol. Symp., 2005, pp. 63-69. 
[7] R. E. Hebner, "Research at the University of Texas at Austin," in Proc. IEEE Elect. Ship Technol. Symp., 2005, pp. 34-38.

[8] V. Caliskan, D. J. Perreault, T. M. Jahns, and J. G. Kassakian, "Analysis of three-phase rectifiers with constant-voltage loads," IEEE Trans. Circuits Syst. I, Fundam. Theory Appl., vol. 50, no. 9, pp. 1220-1226, Sep. 2003.

[9] S. D. Sudhoff and O. Wasynczuk, "Analysis and average-value modeling of line-commutated converter-synchronous machine systems," IEEE Trans. Energy Convers., vol. 8, no. 1, pp. 92-98, Mar. 1993.

[10] H. Macbahi, A. Ba-Razzouk, and A. Cheriti, "Decoupled parallel simulation of power electronics systems using Matlab-Simulink," in Proc. Int. Conf. Parallel Comput. Elect. Eng. PARELEC, 2000, pp. 232-236.

[11] P. D. Evans and P. R. Close, "Harmonic distortion in PWM inverter output waveforms," Proc. Inst. Elect. Eng.-Elect. Power Appl., vol. 134, no. 4, pp. 224-232, Jul. 1987.

[12] N. Mohan, T. Underland, and W. Robbins, Power Electronics: Converters, Applications, and Design. New York: Wiley, 1989.

[13] Piecewise Linear Element Circuit Simulation for Simulink (PLECS). Zurich, Switzerland: Plexim GmbH. [Online]. Available: http://www. Plexim.com

[14] D. C. White and H. H. Woodson, Electromechanical Energy Conversion. New York: Wiley, 1959.

[15] Y. Zhao and T. A. Lipo, "Space vector PWM control of dual three-phase induction machine using vector space decomposition," IEEE Trans. Ind. Appl., vol. 31, no. 5, pp. 1100-1109, Sep./Oct. 1995

[16] H. A. Toliyat, S. P. Waikar, and T. A. Lipo, "Analysis and simulation of five-phase synchronous reluctance machines including third harmonic of airgap MMF," IEEE Trans. Ind. Appl., vol. 34, no. 2, pp. 332-339, Mar./Apr. 1998.

[17] J. M. Apsley, S. Williamson, A. C Smith, and M. Barnes, "Induction motor performance as a function of phase number," Proc. Inst. Elect. Eng., vol. 153, no. 6, pp. 898-904, Nov. 2006.

[18] G. Kupier, The Wageningen Propeller Series. Wageningen, The Netherlands: MARIN Publ., May 1992.

[19] A. S. Kinson, J. E. Hill, D. Eraut, C. French, and R. Tumulty, "Motor load train calculations for a land based demonstrator for marine electrical networks (DMEN)," in Proc. IEE Conf. Power Electron., Mach. Drives, 2004, vol. 1, pp. 373-378.

[20] I. M. Elders, P. J. Norman, J. D. Schuddebeurs, C. D. Booth, G. M. Burt, J. R. McDonald, J. Apsley, M. Barnes, A. Smith, S. Williamson, S. Loddick, and I. Myers, "Modelling and analysis of electro-mechanical interactions between prime-mover and load in a marine IFEP system," in Proc. IEEE Elect. Ship Technol. Symp., 2007, pp. 77-84.

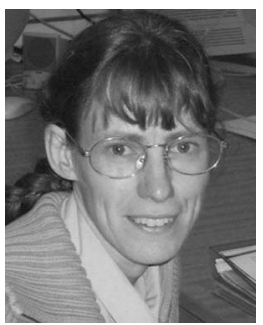

Judith M. Apsley (M'05) received the B.A. degree from Cambridge University, Cambridge, U.K., in 1986, and the Ph.D. degree from the University of Surrey, Surrey, U.K., in 1996.

She had been with Westland Helicopters (19821987), ERA Technology (1987-1995), and a small software company (1996-2001) before joining The University of Manchester (formerly University of Manchester Institute of Science and Technology), Manchester, U.K., as a Research Associate, where she has been a Lecturer since 2008. Her main research interests include the modeling and control of electrical drives.

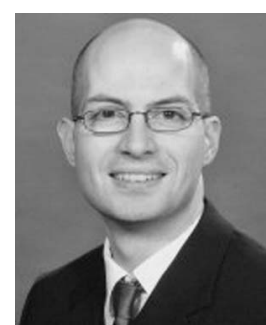

Mike Barnes received the B.Eng. and Ph.D. degrees in engineering from The University of Warwick, Warwick, U.K., in 1993 and 1998, respectively.

Since 1997, he has been a Member of the Academic Staff in the School of Electrical and Electronic Engineering, The University of Manchester (formerly University of Manchester Institute of Science and Technology), Manchester, U.K., first as a Lecturer and then as a Senior Lecturer. His principal research interests include power electronics applied to power systems and transportation.

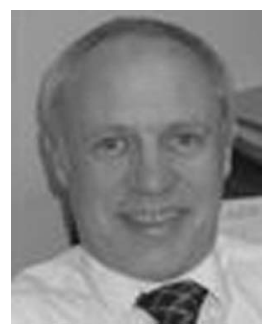

Alexander C. Smith (M'89-SM'02) received the B.Sc.Eng. and Ph.D. degrees from Aberdeen University, Aberdeen, U.K., in 1977 and 1980, respectively.

$\mathrm{He}$ had academic appointments at Imperial College, London, U.K. (1983-1990), and The University of Cambridge, Cambridge, U.K. (1990-1997). In 1997, he was with Invensys Brook Crompton as Head of Research, responsible for motor technology. Since 2000, he has been with The University of Manchester (formerly University of Manchester Institute of Science and Technology), Manchester, U.K., where he has been a Professor of electrical machines in the School of Electrical and Electronic Engineering since 2007 and is currently the Director of the Rolls-Royce University Technology Centre in Electrical Systems for Extreme Environments. His research interests include the design and modeling of motors, generators, and drives.

Dr. Smith is a Fellow of the Institute of Engineering and Technology (formerly Institution of Electrical Engineers (IEE), U.K.) and the past Chairman of the IEE Professional Network-Power Conversion and Applications.

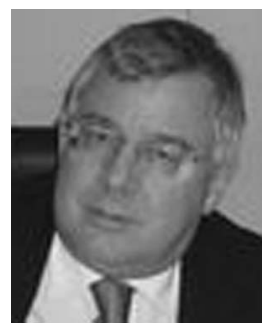

Steve Williamson (M'81-SM'88-F'95) received the B.Sc. and Ph.D. degrees from the Department of Electrical Engineering, Imperial College, London, U.K.

He first took up a lectureship at Aberdeen University, Aberdeen, U.K. In 1981, he moved back to Imperial College, first as a Senior Lecturer and then as a Reader. In 1989, he was a Professor with the Department of Engineering, Cambridge University, Cambridge, U.K., and then, shortly afterward, a Fellow with St. John's College, Cambridge. He became the Technical Director of Brook Hansen in 1997, which was then part of the BTR Group. Several takeovers and reorganizations saw him back in academia at The University of Manchester, Manchester, U.K., as the Head of the School of Electrical and Electronic Engineering. In 2009, he was appointed as Deputy Vice-Chancellor (Research and Innovation) at the University of Surrey, Guildford, U.K.

Dr. Williamson is a Fellow of the Institution of Engineering and Technology (formerly Institution of Electrical Engineers (IEE), U.K.) and the Royal Academy of Engineering.

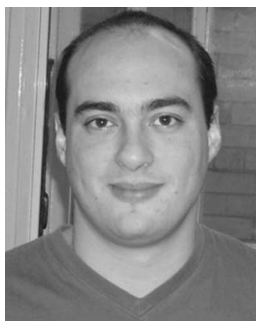

Aurelio González-Villaseñor received the B.Sc. degree in mechanical and electrical engineering from the Instituto Tecnológico de Estudios Superiores de Monterrey, Campus Estado de México, Monterrey, Mexico, in 2000, and the Ph.D. degree in electrical engineering from The University of Manchester, Manchester, U.K., in 2006.

$\mathrm{He}$ is currently a Research Associate with the Power Conversion Group, School of Electrical and Electronic Engineering, The University of Manchester.

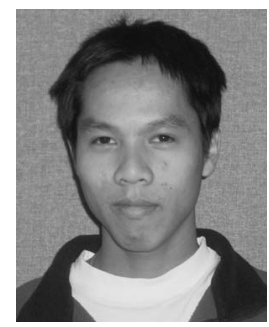

Jeroen D. Schuddebeurs received the B.Sc. degree in maritime operations from the Hogeschool Zeeland, Vlissingen, The Netherlands, and the M.Sc. degree in marine electrical power technology from Newcastle University, Newcastle upon Tyne, U.K. $\mathrm{He}$ is currently working toward the Ph.D. degree in electronic and electrical engineering at the University of Strathclyde, Glasgow, U.K.

$\mathrm{He}$ is a Research Assistant with the Institute of Energy and Environment, Department of Electronic and Electrical Engineering, University of Strathclyde. His research interests include the dynamic modeling and simulation of moreelectric marine power systems. 


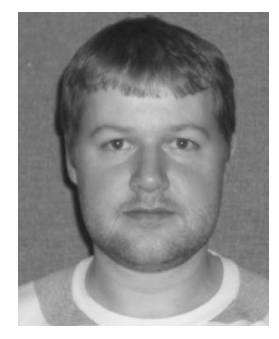

Patrick J. Norman received the B.Eng. degree in electrical and electronic engineering from the University of Strathclyde, Glasgow, U.K., where he is awaiting examination for the Ph.D. degree.

$\mathrm{He}$ is currently a Research Fellow with the Institute for Energy and Environment, Department of Electronic and Electrical Engineering, University of Strathclyde. His research interests include the modeling and simulation of more-electric marine and aerospace power systems, the analysis of electrical-mechanical interactions within these environments, and the fault response of power-electronic-based dc distribution systems.

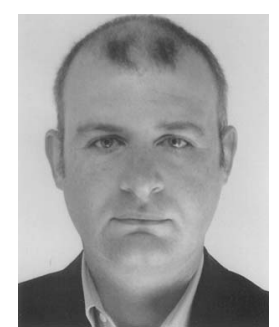

support systems.
Campbell D. Booth received the B.Eng. and Ph.D. degrees in electrical and electronic engineering from the University of Strathclyde, Glasgow, U.K.

$\mathrm{He}$ is currently a Lecturer with the Institute for Energy and Environment, Department of Electronic and Electrical Engineering, University of Strathclyde. His research interests include power system protection; plant condition monitoring and intelligent asset management; applications of intelligent system techniques to power system monitoring, protection, and control; knowledge management; and decision

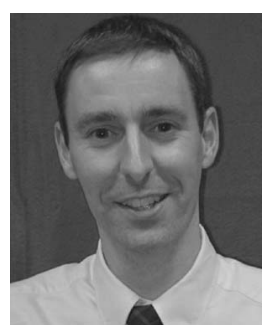

Graeme M. Burt (M'95) received the B.Eng. and $\mathrm{Ph} . \mathrm{D}$. degrees in electrical and electronic engineering from the University of Strathclyde, Glasgow, U.K.

$\mathrm{He}$ is currently the Chair in Power Systems with the Institute for Energy and Environment, Department of Electronic and Electrical Engineering, University of Strathclyde, where he is the Director of the Rolls-Royce University Technology Centre in Electrical Power Systems. His current research interests include network integration of distributed generation, power system modeling and simulation, and power system design.

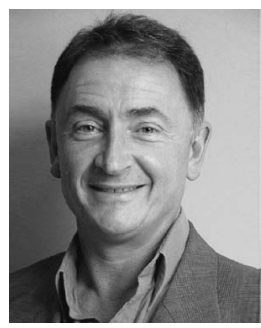

J. R. McDonald (M'90) received the B.Sc., M.Sc., and Ph.D. degrees in electrical and electronic engineering from the University of Strathclyde, Glasgow, U.K.

$\mathrm{He}$ is currently the Director of the Institute for Energy and Environment, Department of Electronic and Electrical Engineering, University of Strathclyde, which is one of the largest power engineering research groups internationally, with over 200 academic, research, and technical staffs. He was appointed as Principal at Strathclyde from 2009. In 2007, he became the Director of the Glasgow Research Partnership in Engineering. His research interests include power system protection and control, distributed generation, and active network management. He has coauthored over 500 journal and conference papers and three books. 